\title{
Uni-versidade multi-versa? Reflexões sobre a formação de professores do curso de Licenciatura em Pedagogia do Campo no distrito de Caramujo, Cáceres/MT
}

\author{
Amanda Pereira da Silva Azinari ${ }^{1}$, Odimar João Peripolli ${ }^{2}$ \\ ${ }^{1}$ Universidade do Estado de Mato Grosso - UNEMAT. Departamento de Pedagogia. Campus Juara. Rod. \\ Juara/Brasnorte, zona rural, s/n. Juara - MT. Brasil. amandaps_jra@htomail.com. ${ }^{2}$ Universidade do Estado de \\ Mato Grosso - UNEMAT.
}

RESUMO. O presente texto tem o objetivo de provocar reflexões sobre uma experiência vivenciada no curso de Licenciatura em Pedagogia do Campo, ofertado na modalidade parceladas, no distrito de Caramujo, localizado no município de Cáceres/MT. A experiência ocorreu em 15 dias de aulas ministradas na disciplina de Gestão e Políticas da Educação do Campo ocorrida no mês de março de 2016. Elaboramos um diálogo sobre a Universidade, Educação do Campo e formação de professores/as a partir dessas experiências. Utilizaram-se para a escrita deste texto relatos de acadêmicos/as disponíveis no memorial reflexivo adotado como um critério avaliativoreflexivo. O mesmo foi utilizado para iniciar as aulas, e ainda, no decorrer das reflexões, serviu de instrumento de diálogo entre professora-acadêmicos/as e acadêmicos/as-acadêmicos/as. Foi importante, pois permitiu a compreensão de alguns conceitos que envolvem a Educação do Campo e pensar sobre a relação entre as histórias de vida e a ausência/presença da escola do/no campo.

Palavras-chave: Universidade, Formação de Professores, Educação do Campo, Pedagogia do Campo. 


\title{
A multi-versa university? Reflections on the training of teachers of the graduation course in Pedagogy of the Countryside in the district of Caramujo, Cáceres/MT
}

\begin{abstract}
The present text has the objective of provoking reflections about an experience lived in the Pedagogy of the Countryside undergraduate course, offered in the modality of installments, in the district of Caramujo, located in the city of Cáceres/MT. The experience occurred in 15 days of classes taught in the discipline of Management and Policies of Rural Education that occurred in March 2016. We developed a dialogue about the University, Rural Education and teacher formation from these experiences. For the writing of this text, the stories of academics available in the reflective memorial adopted as an evaluation-reflexive criterion were used. The same was used to start the classes, and also, in the course of the reflections, served as an instrument of dialogue between teacheracademics and academic-academics. It was important because it allowed the understanding of some concepts that involve the Rural Education and to think about the relation between the life histories and the absence/presence of the school of/in the countryside.
\end{abstract}

Keywords: University, Teacher of Formation, Rural Education, Pedagogy of the Countryside. 


\section{Multi-versa Uni-versidad? Reflexiones sobre la formación de profesores del Curso de Licenciatura en Educación del Campo en el Distrito de Caramujo, Cáceres/MT}

RESUMEN. El presente texto tiene el objetivo de provocar reflexiones sobre una vivencia en el curso de Licenciatura en Pedagogía del Campo, desarrollado en la modalidad parcelado, en el distrito de Caramujo, ubicado en el municipio de Cáceres/MT. La experiencia ocurrió en 15 días de clases impartidas en la disciplina de Gestión y Políticas de la Educación del Campo ocurrida en el mes de marzo de 2016. Elaboramos un diálogo sobre la Universidad, Educación del Campo y formación de profesores/as. Para la escritura de este texto nos basamos nos relatos de la vida de académicos/as disponibles en el memorial reflexivo adoptado como un criterio evaluativo-reflexivo. El memorial fue utilizado para iniciar las clases, y aún, en el transcurso de las reflexiones, sirvió de instrumento de diálogo entre profesora-académicos/as y académicos/as-académicos/as. Fue importante, pues permitió la comprensión de algunos conceptos que involucran la Educación del Campo y pensar sobre la relación entre las historias de vida y la ausencia/presencia de la escuela del/en el campo.

Palabras clave: Universidad, Formación de Profesores, Educación Rural, Pedagogía del Campo. 


\section{Introdução}

A Uni-versidade, como seu próprio nome já anuncia quer ser universal e unir pessoas. Tal tentativa acompanha a história da Universidade do Estado de Mato Grosso (UNEMAT) que se ergueu sob os sonhos de seus conterrâneos e migrantes que por aqui construíram suas trajetórias de vida, e nela, depositaram suas expectativas por um espaço de formação acadêmica, mas, sobretudo, humana e política.

A expansão desta uni-versidade de que Maldonado (1995) se referia, de fato tem se avançado neste Estado, embora haja ausência de um planejamento capaz de atender de maneira justa todas as pessoas, tendo em vista um crescimento considerável de cursos e campus nos últimos anos, porém, sem grandes investimentos na infraestrutura, em acervo bibliográfico e material didáticopedagógico suficientes para atender a demanda.

Apesar dos desafios postos a esta universidade, a mesma tem servido como alternativa de formação superior para populações distantes geograficamente e marginalizadas ao longo da história. Apresenta-se como referência nacional por sua ousada forma de se organizar no interior do Estado e ofertar cursos para a população sem terra, camponesa, assentados, indígenas, a exemplo do Terceiro Grau Indígena, Graduação em Agronomia para os movimentos sociais, a Pedagogia da Terra para professores/as do campo, entre outras modalidades ofertadas em turmas especiais, ou ainda, de maneira recorrente, como é o caso da Faculdade Intercultural Indígena instalada no município de Barra do Bugres.

Neste contexto, nos sentimos parte desta universidade por termos nossa formação superior (o que inclui graduação, especialização e mestrado), cursada nela, e, atualmente, tendo-a enquanto lócus de trabalho.

O texto objetiva refletir sobre uma experiência com o curso de Licenciatura em Pedagogia do Campo, ofertado na modalidade parceladas, no distrito de Caramujo, localizado no município de Cáceres/MT. A experiência ocorreu em 15 dias de aulas ministradas na disciplina de Gestão e Políticas da Educação do Campo ocorrida no mês de março de 2016 e suscita reflexões pertinentes à formação docente para as escolas do campo.

\section{A Universidade do Estado de Mato Grosso e a experiência com a modalidade parceladas na formação de professores/as.}

O Brasil, durante a década de 1970, assim como diversos países da América 
Latina, vivenciava o amargo abandono por parte das políticas públicas agrárias e elitistas. Mato Grosso estava para o Brasil, assim como, o Brasil estava para os países desenvolvidos economicamente, um lugar emergente. A Universidade do Estado de Mato Grosso surge em 1978, não com esta nomenclatura e nem com o caráter público, mas como Instituto de Educação. Foi um contexto de recente conquista da democracia com a Constituição Federal de 1988 e também, num período de grandes fluxos migratórios condicionados à ocupação da Amazônia e de seus "vazios" demográficos como ressaltou Martins (2009). Sob olhares dos colonizadores, somos conhecidos como um país do "terceiro mundo", mas constituído a partir da exploração e genocídio de povos indígenas e do campo.

Neste contexto, concordamos com Maldonado (1995) quando refletiu sobre este passado sombrio face às desigualdades sociais ainda por serem sanadas.

Hoje temos uma certeza. A da impossibilidade de se apagar o passado, de negá-lo, de desconsiderálo. E isso nos dá a convicção de que qualquer expectativa de mudança e avanço passa pela busca do alicerçamento de alianças amplas e sólidas, pela ciência da complexidade das relações em uma nação de pluralidade étnica e política, pouca memória e consequente percepção histórica, com fragilíssima vivencia cidadã e imersa em um fosso abismal de diferenças sociais e econômicas. (Maldonado, 1995, p. 13).

Neste caminho, em meio a contradições e avanços é que se edifica a UNEMAT, cuja característica principal é a interiorização da formação superior no Estado de Mato Grosso, e nasce na tentativa de sanar demandas apresentadas pelo Estado num momento em que a formação docente se fazia escassa. Faziase uma alternativa para superar os desafios sociais, econômicos e ambientais.

Inicialmente, surge como Instituto de Educação Superior de Cáceres, para, posteriormente, após inúmeros embates e lutas, transformar-se em uma universidade pública no ano de 1993, instituída pela Lei complementar $n^{\circ} 30$, Resolução Nº 001/95CEE/MT. Este estatuto evidenciava as características da UNEMAT.

Art. $1^{\circ}$ - A Universidade do Estado de Mato Grosso - UNEMAT -, com sede e foro no município de Cáceres, e atuação em todo o Estado de Mato Grosso, é uma entidade de Direito Público, sem fins lucrativos, mantida pela Fundação Universidade do Estado de Mato Grosso - FUEMAT, gozando de autonomia didáticopedagógica, administrativa, financeira, regendo-se pelo atual Estatuto e legislação afim. (Mato Grosso, 1995).

Devido à extensão territorial e as demandas apresentadas, surge à modalidade "parceladas" no ano de 1992. 
Essas experiências de formação de professores foram as primeiras a atenderem uma formação para professores do campo na região.

Segundo informa a página oficial da UNEMAT (www.unemat.br> Recuperado em 02 maio, 2016), o Programa Parceladas foi criado em 1992 como uma modalidade diferenciada de ensino, com o objetivo de atender inúmeras demandas de formação docente em diferentes regiões do estado de Mato Grosso. Os cursos são presenciais, alguns em regime parcelado e outros em regime contínuo, ofertados em rede continuada, para a formação em serviço de servidores públicos da educação básica do estado de Mato Grosso.

Atualmente a universidade possui dezessete (17) cursos que atendem nesta modalidade conforme quadro abaixo:

\begin{tabular}{|c|c|c|}
\hline $\begin{array}{c}\text { Município/ } \\
\text { Campus/Núcleo }\end{array}$ & Curso & Formação \\
\hline \multirow[t]{2}{*}{ Matupá } & Licenciatura & primeira \\
\hline & Matemática & licenciatura \\
\hline \multirow[t]{2}{*}{ Matupá } & Licenciatura & primeira \\
\hline & História & licenciatura \\
\hline \multirow[t]{2}{*}{ Matupá } & Licenciatura & primeira \\
\hline & Química & licenciatura \\
\hline \multirow[t]{2}{*}{ Luciara } & Letras & primeira \\
\hline & Português/Inglês & licenciatura \\
\hline \multirow[t]{2}{*}{ Luciara } & Letras & primeira \\
\hline & Português/Espanhol & licenciatura \\
\hline Luciara & Pedagogia & primeira \\
\hline
\end{tabular}

\begin{tabular}{|c|c|c|}
\hline & Campo & licenciatura \\
\hline Luciara & $\begin{array}{l}\text { Licenciatura } \\
\text { Química }\end{array}$ & $\begin{array}{l}\text { primeira } \\
\text { licenciatura }\end{array}$ \\
\hline $\begin{array}{l}\text { Cáceres } \\
\text { (Distrito } \\
\text { Caramujo) }\end{array}$ & $\begin{array}{l}\text { Licenciatura } \\
\text { Pedagogia } \\
\text { Campo }\end{array}$ & $\begin{array}{l}\text { primeira } \\
\text { licenciatura }\end{array}$ \\
\hline $\begin{array}{l}\text { São José dos } \\
\text { Quatro Marcos }\end{array}$ & $\begin{array}{l}\text { Licenciatura } \\
\text { Pedagogia }\end{array}$ & $\begin{array}{l}\text { primeira } \\
\text { licenciatura }\end{array}$ \\
\hline $\begin{array}{l}\text { São José dos } \\
\text { Quatro Marcos }\end{array}$ & Agroecologia & Tecnólogo \\
\hline Rio Branco & $\begin{array}{l}\text { Licenciatura } \\
\text { Pedagogia }\end{array}$ & $\begin{array}{l}\text { primeira } \\
\text { licenciatura }\end{array}$ \\
\hline Rio Branco & $\begin{array}{l}\text { Licenciatura } \\
\text { Matemática }\end{array}$ & $\begin{array}{l}\text { primeira } \\
\text { licenciatura }\end{array}$ \\
\hline $\begin{array}{l}\text { Mirassol } \\
\text { Oeste }\end{array}$ & Ciências Contábeis & Bacharelado \\
\hline $\begin{array}{l}\text { Mirassol } \\
\text { Oeste }\end{array}$ & Administração & Bacharelado \\
\hline Nova Lacerda & Ciências Contábeis & Bacharelado \\
\hline Campus de Júlio & Ciências Contábeis & Bacharelado \\
\hline $\begin{array}{l}\text { Vila Bela da } \\
\text { Santíssima } \\
\text { Trindade }\end{array}$ & Agroecologia & Tecnólogo \\
\hline
\end{tabular}

Fonte: Disponível em: www.unemat.br. Recuperado em 02 de maio, 2016.

A maioria desses cursos de licenciatura é ofertada em parceria entre Governo Federal e governos estaduais através do Plano Nacional de Formação de Professores da Educação Básica (PARFOR). Trata-se, segundo a Coordenação de Aperfeiçoamento de Pessoal de Nível Superior (CAPES) conforme consta no site (http://www.capes.gov.br/ Recuperado em 10 de junho, 2016), um "Programa emergencial instituído para atender o disposto no artigo 11, inciso III do Decreto no 6.755 , de 29 de janeiro de 2009”. Há a 
oferta de licenciaturas, segunda licenciatura para professores em exercício e formação pedagógica. O objetivo é

O distrito de Caramujo Cáceres/MT: uma microgeografia das gentes pantaneiras

fomentar a formação superior para professores/as da educação básica que estejam em exercício da função.

Figura 1 - Localização de Cáceres, Distrito de Caramujo.

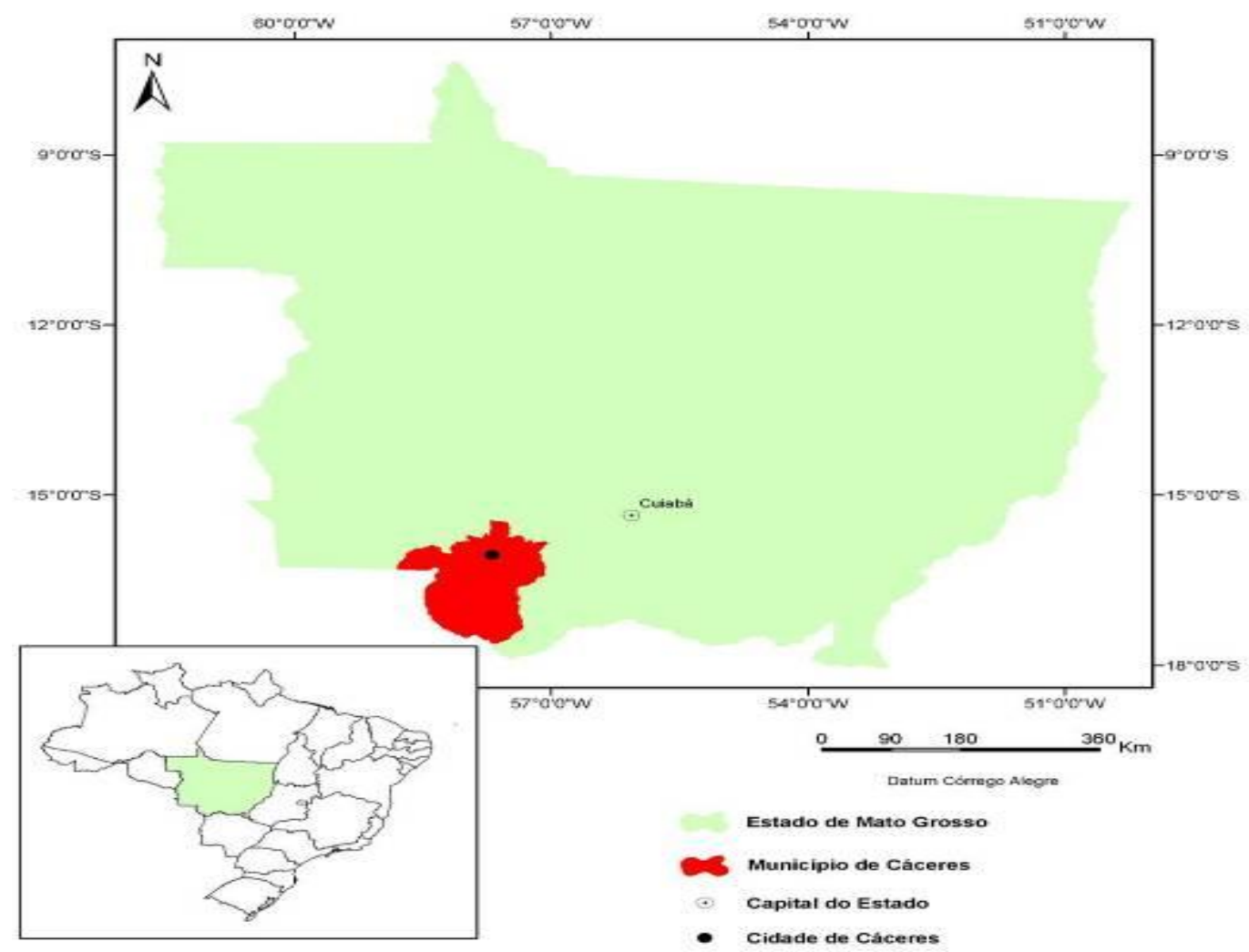

Fonte: http://www2.unemat.br/atlascaceres/index.php?pasta=localizacao. Recuperado em 30 de maio, 2017.

O distrito de Caramujo está localizado no Pantanal mato-grossense distante a $30 \mathrm{~km}$ da sede do município de Cáceres. Surgiu a partir da homologação da Lei n. 5.348/88. Sua configuração territorial é composta por fazendas e uma comunidade com aproximadamente três mil habitantes (Relatos de acadêmicos).

Em visita à comunidade, pode-se observar que ela possui uma Escola Municipal que atende a Educação Infantil e uma escola Estadual que atende o Ensino Fundamental, Ensino Médio Integrado à 
agroecologia, Educação de Jovens e Adultos, e, em convênio com a UNEMAT, campus de Cáceres, a escola estadual oferece sua estrutura física, como sala de aula, banheiros, data show, laboratório de informática para a realização do curso de Licenciatura em Pedagogia do Campo no Núcleo Pedagógico de Cáceres.

O Distrito é considerado uma região de zona rural, ou seja, tem sua organização econômica baseada principalmente em atividades de agropecuária difundida pela concentração de terras sob o poder de fazendeiros. Possui indústria de cerâmicas e laticínio que empregam boa parte de trabalhadores/as que ali residem. Há uma espécie de vila com casas divididas em lotes. Há igrejas, comércios, lanchonetes, e uma pequena feira que fica na BR 070 e faz divisa com os municípios de Mirassol D’Oeste, Barra do Bugres, Nossa Senhora do Livramento, Poconé, Porto Esperidião, Lambari D'Oeste, Glória D'Oeste e República da Bolívia.

A comunidade atendida pelo curso de Pedagogia do Campo é bem diversa e não se trata de professores/as em exercício da profissão conforme prevê o PARFOR, mas atende a trabalhadores/as de variados espaços, como: vigilantes, merendeiras, donas de casa, vendedores de salgados, empregadas domésticas, assistente de dentista, aposentados/as, padeiras, babás, e auxiliar de professores/as da educação infantil (voluntárias ${ }^{\mathrm{i}}$ ).

\section{A Educação do Campo e a Licenciatura em Pedagogia do Campo}

A Educação do Campo nasce como uma modalidade educativa que se contrapõe ao modelo dominante de educação que se consolidou no Brasil a partir da lógica de exclusão difundida pelas práticas pedagógicas, pelo currículo e pela ausência de formação e condições dignas de trabalho de professores/as do campo, além de outras demandas geradas pela estrutura social a que pertencemos, a sociedade capitalista.

Azinari (2016) compreende que a Educação do Campo está inclusa em um projeto em que Outro Mundo é Possível, conforme lembra Dom Pedro Casaldáliga ${ }^{\mathrm{ii}}$, pois se origina de pressupostos e práticas contrários ao que está posto no modo capitalista de conceber o campo, o trabalho, a escola e a própria dinâmica da vida.

O capital, na figura do patrão, ou das empresas multinacionais, ao dispor de mecanismos de dominação controlando os meios de produção, explora os trabalhadores, utiliza-se do discurso do progresso, das monoculturas e transgenia para produzir e, ao mesmo tempo, destruir a biodiversidade do campo, pois interferem 
nos biomas, no solo, nos rios, na vida das pessoas residentes na cidade ou no campo. Estudos realizados por Andrioli e Fuchs (2012) revelam o poder devastador imputado pelo uso de transgênicos no mundo e afirmam que a América Latina não passa de um mercado de testes para essas "tecnologias" para o capital estrangeiro.

Em contraponto a este modelo de sociedade, a proposta educacional da Educação do Campo contesta a desigualdade socioeconômica quando levanta a bandeira da economia solidária em seus assentamentos ou na criação dos cursos de Agroecologia, por exemplo. Contesta a absolutização da propriedade quando marcha coletivamente pelos caminhos tortuosos do acesso a terra e a ocupa, em forma de acampamentos, resistentemente, em busca da Reforma Agrária ainda não consolidada neste país.

Autores/as como Molina e Freitas (2011), Molina (2014, 2015), Fernandes \& Caldart (2000), Caldart (2004, 2012), entre outros, apontaram em seus textos que a luta pela Educação do Campo iniciou-se nos anos 1990, a partir da mobilização dos movimentos sociais do campo, consolidando o que denominam de "Movimento da Educação do Campo iii", É de consenso que as conquistas no campo político foram, de fato, alcançadas nos últimos anos através da mobilização popular. Desses avanços, foram construídas políticas públicas educacionais para a Educação do Campo.

Caldart (2004) assinala que a promulgação da Lei de Diretrizes e Bases da Educação n. 9.394/96 contemplou-se a formação de professores/as. O que não havia era a ideia de uma formação que atendesse as demandas educacionais, sociais e políticas do campo. Com o $1^{\circ}$ Encontro Nacional de Educadores e Educadoras na Reforma Agrária (ENERA), e, depois, com a $1^{\text {a }}$ Conferência Nacional pela Educação Básica do Campo no ano de 1998 é que se intensificaram as mobilizações que denunciaram as demandas para a formação humana no e do campo, desde a educação infantil à formação superior, haja vista, a oferta de uma educação rural precarizada e abandonada pelos órgãos públicos (in)competentes.

No Brasil, cerca de 180 mil professores/as do campo estavam sem formação adequada (Molina, 2014). O Programa Nacional de Educação na Reforma Agrária (PRONERA), criado em 1998, nasce como possibilidade de promover a formação de professores/as do campo a partir da promulgação do Programa de Apoio à Formação Superior em Licenciatura em Educação do Campo 
(PROCAMPO) (2012), que legitimou as demandas anteriormente levantadas durante as conferências e encontros. Logo mais, configurou-se em uma política específica para atender a formação docente para professores/as do campo.

A partir da Articulação Nacional por uma Educação Básica do Campo, de encontros e reuniões, produziram-se materiais importantes para se pensar/concretizar uma educação específica aos povos do campo. As primeiras produções podem ser encontradas na coleção "Por uma Educação Básica do Campo" que demarcam os objetivos, princípios, desafios e sonhos, antes almejados pelas populações do campo (Benjamin \& Caldart, 2000).

Azinari (2016) ressalta que, de lá para cá, inúmeros avanços no campo legal foram alcançados, sempre com o protagonismo dos movimentos sociais do campo, em especial o Movimento dos Trabalhadores Rurais Sem Terra (MST) que, desde sua gênese na década de 1980, marchou, acampou, resistiu e ocupou diversos espaços para além da terra.

A partir das Diretrizes Operacionais para a Educação Básica das Escolas do Campo (Resolução n. 1/2002 CNE/CEB), avanço significativo do ponto de vista legal, uma vez que contemplou a especificidade da formação pautada na promoção da população do campo, sua autonomia e identidade, fruto das lutas dos movimentos sociais do campo.

A formação inicial e continuada está assegurada no Art. 12 da referida resolução. Em seu paragrafo único observa-se: "Os sistemas de ensino, de acordo com o artigo 67 da LDB desenvolverão políticas de formação inicial e continuada, habilitando todos os professores leigos e promovendo o aperfeiçoamento permanente dos docentes" (Brasil, 2002). Compreende-se, então, que o campo, gerado pela exclusão de trabalhadores/as, esteve à margem de políticas públicas, em especial, educacionais. Por isso, ao referir-se ao/as "professores/as leigos/as", afirma-se também a existência de um/a agente social tão abandonado/a como o espaço em que emerge.

Therrien (1993) estudou sobre a constituição da professora leiga e a entende como um ser social e político dotado de conhecimentos vivenciados na experiência da prática pedagógica, e ainda, nas lutas travadas durante sua trajetória de vida. A professora leiga do campo é gerada por esta estrutura de exclusão, e foi por muito tempo, responsabilizada pelo fracasso escolar. 
$\mathrm{O}$ autor ainda reconhece que as mulheres são a maioria expressiva na docência seja no campo ou na cidade, cujas comprovações aparecem nos dados do Instituto Nacional de Estudos e Pesquisas Anísio Teixeira [INEP] (2007).

Como forma de romper com este abandono, contemplou-se, a partir de inúmeras lutas, uma política que assegurasse o direito a uma formação, não apenas em nível superior, mas a partir da compreensão de que o campo é um espaço de produção de vida e de conhecimento, haja vista que a educação é entendida aqui, como uma prática social (Brasil, 1996).

Assim, a Resolução n. 01/2002

CNE/CEB assegura que:

Art. 13. Os sistemas de ensino, além dos princípios e diretrizes que orientam a Educação Básica no país, observarão, no processo de normatização complementar da formação de professores para o exercício da docência nas escolas do campo, os seguintes componentes:

I - estudos a respeito da diversidade e o efetivo protagonismo das crianças, dos jovens e dos adultos do campo na construção da qualidade social da vida individual e coletiva, da região, do país e do mundo;

II - propostas pedagógicas que valorizem, na organização do ensino, a diversidade cultural e os processos de interação e transformação do campo, a gestão democrática, o acesso ao avanço científico e tecnológico e respectivas contribuições para a melhoria das condições de vida e a fidelidade aos princípios éticos que norteiam a convivência solidária e colaborativa nas sociedades democráticas (Brasil, 2002).

A referida Resolução, ao regulamentar os direitos dos povos do campo no que diz respeito a uma educação própria e com qualidade social, é um instrumento legítimo e legal que preconiza a identidade de cada escola, devido à diversidade existente no campo brasileiro.

A essa identidade, Peripolli (2009) confirma que as Diretrizes têm a "cara" desses sujeitos que vivem na e da terra.

As Diretrizes representam, não só o amparo legal que possibilite operacionalizar/construir novas propostas de educação para os trabalhadores do campo, como o resgate, a conquista dos direitos negados aos povos do campo ao longo dos anos. Pode-se dizer que estas têm a "cara" destes sujeitos que vivem na e da terra. O campo, com uma legislação educacional própria, representa, acima de tudo, a vitória dos mais diferentes movimentos sociais populares na luta contra toda forma de expropriação/exploração patrocinada pelo capital: a expropriação da terra, do trabalho, do saber. Uma vitória que vai se constituindo no cotidiano. (Peripolli, 2009, p. 118).

Para consolidar essa "cara" ou a identidade da escola do campo, foi preciso olhar para os sujeitos desse processo: trabalhadores e trabalhadoras, crianças, jovens e idosos/as moradores do campo. Para que essas vivências estivessem presentes no contexto da escola do campo, 
as Diretrizes, além de representarem os anseios da população do campo, instituíram também uma política específica de formação de professores e professoras da Educação do Campo, a fim de se construir uma proposta curricular ancorada na realidade onde a escola estivesse inserida.

Com acúmulo de algumas experiências $^{\text {iv }}$ após a criação do Pronera, do Procampo, ainda era preciso ampliar a oferta da modalidade educativa, uma vez que, na maioria das escolas do campo, havia apenas professores/as considerados/as leigos/as.

Segundo Arroyo (2012), as demandas dos movimentos sociais para construir uma proposta de formação de professores específica ao campo foram debatidas e organizadas na "Conferência Nacional realizada em 2004, dando origem à Secretaria de Educação Continuada, Alfabetização, Diversidade e Inclusão do Ministério da Educação (Secad/MEC), ao Programa de Apoio às Licenciaturas em Educação do Campo (Procampo)" (Arroyo, 2012, p. 362).

Essas demandas foram sistematizadas na "Proposta do Plano Nacional de Formação de Profissionais da Educação do Campo" em 2005. Somente em 2008, com a homologação da Resolução CNE/CEB no 2, de 28 de abril de 2008, estabeleceram-se diretrizes complementares para atendimento das políticas públicas da educação básica que reconhecia a diversidade dos povos do campo em suas especificidades; Já a Lei $12.960 / 2014$ considera que o fechamento das escolas do campo, deve preceder de diagnóstico e parecer da secretaria de educação, entre outras possibilidades de manutenção da vida no campo, a partir da política educacional.

Caldart (2004) compreende que o campo e seus sujeitos possuem uma dinâmica própria, com modos de se organizar e viver peculiares ao espaço em que se reproduzem. Por isso, há a necessidade de se pensar em uma Pedagogia do Movimento Sem Terra como forma de resistir e dar continuidade às lutas pela conquista dos direitos sociais. Esses conhecimentos são indispensáveis para a manutenção da vida no campo, o que justifica a formação de professores/as que estejam vinculados a esta realidade.

Compreende-se que os cursos de licenciatura em Pedagogia do Campo são resultados das lutas sociais, e, ao transformarem-se em políticas públicas, evidenciam os avanços construídos pelas coletividades nos últimos 18 anos.

Uma formação amparada no sentimento de justiça social precisa estar conectada a uma mudança radical da 
sociedade. Pequenos avanços, apesar de serem motivos de alegria, são, sem sombra de dúvidas, a mínima fatia de um direito.

Para a consolidação de propostas formativas que problematizem, e, de fato, modifiquem a estrutura social vigente, compreendemos a necessidade de questionar qual tem sido “... o papel da educação na construção de outro mundo possível? Como construir uma educação cuja principal referência seja o ser humano? Como se constitui uma educação que realize as transformações políticas, econômicas, culturais e sociais necessárias?" (Mészáros, 2008, p. 10).

A construção de uma sociedade justa perpassa pela desconstrução desta sociedade cindida em classes (Marx, 2001). E a universidade deve fazer parte desta transformação. Concordamos com Molina (2014, p. 273) quando entende que “a universidade pública é um aparelho tradicional de hegemonia, no interior do qual se apresenta uma diversidade de projetos em disputa pela direção intelectual e moral da sociedade".

Diante deste posicionamento teórico e político, procurou-se contemplar a formação docente no curso de Licenciatura em Pedagogia do Campo a partir das experiências vivenciadas durante a disciplina: Gestão e Políticas da Educação do Campo.
As experiências pedagógicas no curso de Pedagogia do Campo no distrito do Caramujo: reflexões e memórias escolares na formação docente

Houve, inicialmente, o processo seletivo para que pudesse participar da modalidade como professora. Naquele momento, manifestei a intenção de qual disciplina ministrar. Optei pela disciplina de Gestão e Políticas da Educação do Campo, que seria ministrada numa turma do $5^{\circ}$ semestre. Fui selecionada e ministrei as aulas de 02/03/2016 a 17/03/2016.

O grupo discente se mostrou receptivo e interessado à proposta de trabalho que seria desenvolvida no período em questão. $\mathrm{O}$ cronograma e o plano de ensino foram revistos e reelaborados durante as aulas para atender a realidade da turma, cuja composição é: 42 acadêmicos/as de idades que variam de 20 a 70 anos de idade; entre eles/as, 6 (seis) eram pessoas do sexo masculino; 36 (trinta e seis) do sexo feminino. Isto confirma a reprodução de um dado nacional sobre a participação maciça de mulheres nas licenciaturas Inep (2009).

Como não conhecia a turma, o planejamento ocorreu pelas trocas obtidas junto à coordenação da modalidade localizada na sede administrativa UNEMAT de Cáceres, que nos forneceu as 
informações necessárias para tal. A ementa da disciplina assim se apresentou:

- Fundamentos teóricoconceituais das Políticas Públicas de Educação do Campo.

- Educação do Campo como direito humano no contexto da política de desenvolvimento com igualdade social dos movimentos sociais e sindicais.

- História dos movimentos sociais do campo no Brasil.

- Perspectiva histórica das políticas de Educação Rural e do Campo no Brasil.

- As políticas de Educação do Campo percebidas na sua interlocução dialógica entre o Estado e os Movimentos Sociais.

- Gestão democrática.

- Gestão pedagógica da educação escolar do campo.

- Escola formadora do ser humano articulada com um projeto de emancipação humana. (Projeto Político Curricular, 2013).

A partir da ementa, elegemos como objetivo geral da proposta pedagógica, a apropriação de conhecimentos técnicocientíficos e metodológicos indispensáveis à compreensão da gestão e políticas da Educação do Campo.

No primeiro encontro nos apresentamos. Narrei sobre alguns percursos de minha história como professora e minha trajetória de formação. Naquele instante, deixei meu coração se apresentar por mim, e enquanto eu falava, também ia me refazendo, como ser inacabado que sou. Logo após esta conversa inicial, fui tentando costurar à minha trajetória a minha imersão como trabalhadora numa sociedade configurada sob a égide do modelo capitalista.

O processo de reestruturação produtiva alterou o cenário nacional no que diz respeito ao mundo do trabalho. No contexto do capital, a profissão docente tem sido compreendida "... como um trabalho tipicamente capitalista" (Hypólito, 1997, p. 89). Tal afirmativa se sustenta a partir da concepção de Marx, quando afirma que todo trabalho produtivo é aquele emergido para a valorização do capital, ou seja, o que produz a mais valia. Assim, Marx (2001, p. 219) entende que "o trabalhador[a] trabalha sob o controle do capitalista, a quem pertence seu trabalho. O capitalista cuida para que o trabalho se realize de maneira apropriada e em que se apliquem, adequadamente, os meios de produção ...”.

Ao recontar a minha trajetória como mulher, professora e trabalhadora inserida dentro desta sociedade de classes, observei naquele instante que parte dos/as acadêmicos/as se reconheciam em minhas memórias. Ora com palavras que narravam a exploração a que eram submetidos/as, ora com olhares e ouvidos atentos ao ponto de me tocarem com um silêncio ensurdecedor. Pude explorar e conhecer um pouco das 
vidas que ali estavam a partir de um vídeo com a música "A lista", de Oswaldo Montenegro, e, para que pudessem acompanhar a letra, levei na versão impressa.

A música foi utilizada apenas como instrumento mobilizador para que contassem um pouco de si. Após este momento, pedi para que desenhassem o "Rio da vida". Esta foi uma dinâmica para que expusessem, através de uma atividade artística, suas impressões sobre os percursos da vida, suas histórias e memórias de infância até o presente.

Ao contrário da lógica hegemônica presente nos processos de formação docente no país, fundamentados na epistemologia da prática - que desconsidera fatores centrais para a qualificação das práticas docentes, tomando como base condições sociais, econômicas, políticas e culturais, que necessariamente interferem no processo educativo, na licenciatura em Educação do Campo -, partimos de historias individuais e das práticas e saberes docentes, com o cuidado, porém de localizá-las dentro de contextos estruturais muito maiores que as contem. (Molina, 2014, p. 274).

A autora fala da formação em Licenciatura em Educação do Campo ofertada pela Universidade de Brasília (UNB), mas que não se distancia daquilo que acreditamos diante da proposta do curso em análise, pois a intenção de trabalhar com a atividade "rio da vida" foi justamente, fazer com que cada sujeito, ao desenhar e narrar suas histórias, fossem se reconhecendo num contexto mais amplo dentro desta sociedade permeada pelas contradições e conflitos de classe.

Para a captura dos sentidos que a formação superior tem propiciado aos acadêmicos/as, utilizou-se da metodologia da história Oral mediante a escuta das narrativas. As narrativas são instrumentos de coleta de dados que têm ocupado destaque nas pesquisas e no próprio desenvolvimento profissional na formação de professores, pois a centralidade está em compreender certos fenômenos pelo ponto de vista daquele/a que narra, conta e reconta suas experiências. Nesse processo o sujeito reflete e elabora novos pensamentos sobre sua própria história. Para Dias e Engers (2005, p. 510), “aо narrar suas vivências, os professores estão fazendo uma reconstituição de significados dos fatos e experiências, consideradas as mais importantes de suas vidas".

Os diálogos foram sobre as trajetórias de formação escolar e o que os levou ao curso de Pedagogia do Campo. Em uma roda de conversa cada acadêmico/a mostrou seu "rio" e narrou parte de sua história. Alguns/as se emocionaram, contaram momentos difíceis que enfrentaram e que, apesar de tudo, estavam estudando. 
Ao narrar suas histórias, vamos evidenciando o lugar de onde os sujeitos falam. De famílias humildes oriundas de Mato Grosso e outras migrantes de outros estados. Interessante que esse processo de retornar ao tempo passado no momento das socializações das histórias possibilitou observar algumas semelhanças nas trajetórias de vida que são universais, condicionadas social e economicamente. Mas, ao mesmo tempo, revelaram singularidades nesses percursos, segundo Molina (2014) é uma forma de propiciar a reflexão crítica sobre os processos econômicos, sociais, políticos e culturais de cada momento vivido e se localizar num contexto mais amplo.

Acadêmicos/as relataram sobre suas trajetórias e informam:

Minha família veio de São Paulo, tiveram muitas dificuldades na viagem, também viajar com 14 filhos não é fácil. Nasci em Cáceres no ano de 1965 e sempre morei no sítio. Morei um tempo numa fazenda divisa com a Bolívia (Acadêmica, 51 anos). Nasci em São Paulo, na cidade de Birigui. Minha mãe faleceu quando eu tinha um ano de idade, não a conheci. Vim para Mato Grosso com sete anos de idade. Tinha que fazer todo o serviço de casa, para ir à escola era difícil porque era longe, aí eu chegava atrasada (Acadêmica, 69 anos).

Nasci na cidade de Araputanga, morávamos em uma fazenda, Estancia Magalhães. Somos de uma família grande, minha mãe teve 10 filhos e um de criação. A minha mãe já era professora quando eu comecei a estudar, lembro-me muito da escola que estudávamos, era muito simples, de pau a pique e coberta de folha de babaçu e capim de sapé (Acadêmico, 39 anos).

Comecei a estudar com sete anos de idade. Tive uma professora maravilhosa, tive muitas dificuldades para ir à escola, porque eu morava longe. Meus pais são de Mato Grosso e se conheceram numa festa de São Sebastião e tiveram 11 filhos. Com 17 anos eu tive minha primeira filha. Em 2013 ela foi assassinada por um ladrão que tentou roubar nossa casa. Este foi o tempo mais difícil para mim. (Acadêmica, 37 anos).

A maior parte daqueles/as que frequentam o curso de Pedagogia do Campo no distrito de Caramujo são mulheres. Os relatos evidenciam a perpetuação de uma sociedade patriarcal, uma vez que casaram muito cedo, sendo um dos motivos do abandono da escola no momento da infância. Saffioti (2013) acredita que a sociedade patriarcal que nos rege é quem determina o lugar de cada pessoa. A fala das acadêmicas confirma que o machismo está assentado numa relação de poder, em que a mulher, ao se casar, passa a ser propriedade do marido, não podendo escolher aquilo que deseja.

Esta relação está fundada na divisão desigual do trabalho. Para Campos (2011, p. 35), 
A mulher não tem um bom emprego porque tem que conciliar com as responsabilidades de mãe e esposa, e milhares de mulheres não podem deixar de trabalhar devido à condição de pobreza, então tem que se sujeitar aos trabalhos com jornadas parciais, que em geral, estão associados a condições precárias, sem direitos e com baixa remuneração.

Há uma relação hierárquica do trabalho masculino, considerado produtivo (produção econômica) em detrimento do feminino, o reprodutivo (reprodução de filhos/as). Isso justifica a exploração sofrida pelas professoras, quando estas, além das duplas ou triplas jornadas em escolas, têm o "dever do lar" sob sua responsabilidade, reforçando a desigualdade histórica entre os sexos.

A divisão sexual do trabalho determina histórica e culturalmente, não apenas destina homens à esfera produtiva e as mulheres à esfera reprodutiva, como também atrela os primeiros às funções de maior valor social. ... os papéis de assalariamento e na família aparecem como o que são, isto é, não como produto de um destino biológico, mas como um "construto social", resultado das relações sociais. (Freitas, 2007, pp. 12-13).

As acadêmicas do curso de Licenciatura em Educação do Campo carregam a marca da feminilidade em seus corpos e histórias. A falta de oportunidade, inclusive de formação, condicionou à possibilidade de estudar como uma espécie de "salvação". Apesar das dificuldades enfrentadas, percebem que a formação no curso de Pedagogia do campo tem sido uma alternativa de formação, e ao mesmo tempo, tem alimentado perspectivas para melhoria de suas vidas.

Meu sonho é terminar a faculdade e atuar na área de Pedagogia $e$ procurar cada vez mais progredir em meus estudos (Acadêmica, 37 anos).

Fiquei fora de sala de aula por seis anos, jamais imaginei eu, em uma sala de aula fazendo uma faculdade, mas estou gostando muito e pretendo continuar e ir até o fim e quem sabe, se tiver a oportunidade, me tornar uma professora na educação infantil, porque gosto muito de crianças (Acadêmica, 27 anos).

Tive vontade de desistir várias vezes, uma delas foi quando tive que fazer aborto, pois estava grávida de 11 semanas de gêmeos, mas não estavam se desenvolvendo. Foi difícil, mas superei. Tenho outros problemas na família, mas se Deus quiser, vou ultrapassar todas as barreiras e vou terminar a faculdade de Pedagogia do Campo e poder lecionar para outras crianças (Acadêmica, 25 anos).

$O$ curso de Pedagogia do Campo esta sendo de grande importância na minha vida profissional, pois estou adquirindo muitos conhecimentos, que não é apenas ler e escrever, mas de respeito com meus próximos, valorizando cada cultura, religião, as diferenças e métodos de ensino (Acadêmico, 32 anos).

Para a maioria dos/as acadêmicos/as, o curso é uma forma de superação das condições de vida que possuem, mas a 
percepção que apresentaram não está vinculada à ideia de outro campo, pois durante todas as aulas, fazíamos ligação da vida relatada pelos acadêmicos/as nos primeiros dias de aula, com a construção das políticas públicas da Educação do Campo no Brasil. E durante estes processos, afirmavam que não tinham estudado nada a respeito da especificidade da Educação do Campo.

Acredita-se que o campo é mais do que a política difundida pelo agronegócio e da precarização e exploração de trabalhadores/as e o lucro a todo custo. Acreditamos em um campo que é a bandeira dos movimentos sociais do campo, em especial o MST, que defende um projeto de campo ancorado na perspectiva da inclusão social e produtiva, no manejo sustentável e ecológico dos recursos naturais, ou seja, num projeto social justo, solidário e digno de se viver. Concordamos com Fernandes (s/a, p. 02) "pensar o campo como território significa compreendê-lo como espaço de vida, ou como um tipo de espaço geográfico onde se realizam todas as dimensões da existência humana".

Esse mesmo campo defendido pelos movimentos sociais precisa ser redescoberto pelos/as os/as acadêmicos/as, que embora oriundos do campo, há fortemente o ideário de que a cidade é o lugar ideal para viver. Foi perceptível que a comunidade acadêmica de Caramujo não se reconhecia com o "campo" e nem como comunidade rural. Neste sentido é que coadunamos com Neto (2011),

Os cursos de Licenciatura do campo inscrevem-se dentro de propostas políticas que podem ser inovadoras para a escola e para as relações sociais, pois numa sociedade cindida em classes, com interesses diferenciados, o compromisso é com o trabalhador do campo e com a escola que interessa aos setores populares. (Neto, 2011, p. 25).

Por isso, a atividade proposta "rio da vida", seria uma alternativa de conhecer os sujeitos, suas histórias e expectativas de formação e ainda, vincular as demais atividades previstas no planejamento de aula, aos seus contextos de vida, na tentativa de produzir sentido naquilo que falávamos e aprendíamos. O intuito maior foi de que compreendessem que era parte das conquistas da Educação do Campo, e que cada direito conquistado, era também, direito de cada um/a daquela turma, de ter acesso à formação superior de que tanto se orgulhavam em fazer parte.

\section{Algumas considerações}

A política de Educação do Campo e da formação de professores/as do campo é fruto de intensa mobilização e organização dos movimentos sociais e universidades, 
conjuntamente com entidades sindicais e religiosas, que conseguiram o reconhecimento legal da Educação do Campo como um direito dos povos do campo conforme prevê a Resolução n. 01/2002 CNE/CEB.

A oferta de uma modalidade diferenciada e turma única para a Educação do Campo revela, entre outras questões, que esta ainda é uma política educacional em construção, pois a não continuidade da mesma fragiliza um projeto de Educação do Campo que considere as reais necessidades formativas para o lugar em que está inserida.

O próprio acesso ao projeto do curso ocorreu de forma fragmentada, apenas a ementa da disciplina recebida por e-mail, o que dificultou uma compreensão mais ampla dos objetivos do curso e das demais disciplinas, e ainda, o percurso da institucionalização do curso naquela comunidade.

Ainda assim, é possível compreender que a atividade destacada neste texto fez com que os/as acadêmicos/as externalizassem suas memórias e trajetórias, podendo assim, refletir sobre seus próprios contextos de vida como forma de reconhecer-se como ser no e com o mundo (Freire, 1987), ou ainda, como agentes políticos do e no campo. Esta atividade também propiciou uma organização do trabalho mais articulada à vida deles. Houve um processo de formação crítica acerca da contextualização histórica das políticas e a gestão da Educação do Campo de maneira significativa.

Alguns disseram que ainda não haviam estudado sobre a Educação do Campo, que as demais disciplinas não trataram diretamente dos conceitos que a envolvem, e, que por este motivo, afirmaram que as aulas contribuíram para a compreensão sobre a temática e que puderam repensar sobre suas histórias de lutas e desafios, tendo neste curso uma alternativa de uma vida digna e justa.

A experiência aqui relatada contribuiu para entender a lógica da formação ofertada, ainda que de maneira tímida. Porém, como salienta Frigotto (2014), o conhecimento que interessa à classe trabalhadora precisa ajudar a revelar as formas de dominação e alienação, sendo as universidades e as escolas públicas, espaços propícios para pensar a transformação social na medida em que a produção desse conhecimento ajude na compreensão de quais mudanças são necessárias, a fim de que, coletivamente, haja organização para superar as relações sociais geridas pelo capital.

A escola, universidades públicas e os movimentos sociais têm sido uma das 
poucas alternativas para a classe trabalhadora pensar na superação desta sociedade, e neste caso, tomamos a formação da Licenciatura em Pedagogia aqui discutida como uma dessas possibilidades de reflexão, imersão crítica de si e do outro nos processos que constituem a Educação do Campo e pensálo enquanto projeto popular para o enfrentamento dos desafios cotidianos que vivenciamos.

\section{Referências}

Andrioli, A. I., \& Fuchs, R. (Orgs). (2012). Transgênicos: as sementes do mal - a silenciosa contaminação de solos $e$ alimentos. São Paulo: Expressão Popular.

Arroyo, M. G. (2012). Formação de Educadores do Campo. In Dicionário da Educação do Campo. Caldart, R. S. Pereira, I. B., Alentejano, P., \& Frigotto, G. (Orgs.). Rio de Janeiro, São Paulo: Escola Politécnica de Saúde Joaquim Venâncio, Expressão Popular.

Arroyo, M. G., \& Fernandes, B. M. (1999). A educação básica e o movimento social do campo. (Coleção Por Uma Educação Básica do Campo, $\mathrm{n}^{\circ}$ 2). Brasília, DF. Articulação Nacional por uma Educação Básica do Campo.

Azinari, A. P. S. (2016). Constituir a vida numa região de fronteira: trajetórias de mulheres-professoras-trabalhadoras do campo em Juara/MT. (Dissertação de Mestrado). Universidade do Estado de Mato Grosso. Mato Grosso.

Brasil. (1988). Constituição Federal. Recuperado em 05 de abril, 2016 de http://www.planalto.gov.br/ccivil_03/const ituicao/constituicaocompilado.htm.

Brasil. Ministério da Educação. (2002). Conselho Nacional de Educação. Diretrizes Operacionais para a Educação Básica nas Escolas do Campo. Resolução CNE/CEB 1/2002 - Publicação no Diário oficial da união em 9 de abril de 2002.

Benjamin, C., \& Caldart, S. R. (2000). Projeto popular e escolas do campo. (Coleção Por uma Educação Básica do campo, $n^{\circ}$ 3) Brasília, DF. Articulação Nacional Por uma Educação Básica do Campo.

Brasil. Ministério da Educação. (1996). Lei de Diretrizes e Bases da Educação Nacional - LDB Lei N. ${ }^{\circ}$ 9394/96.

Caldart, R. S. (2004). Pedagogia do Movimento Sem Terra. São Paulo: Expressão Popular.

Caldart, R. S. (2012). Caminhos para a transformação da escola. In Aued, B. W., \& Vendramini, C. R. (Orgs.). Temas $e$ problemas no ensino em escolas do campo. São Paulo: Outras Expressões.

Campos, C. S. S. (2011). A face feminina da pobreza em meio à riqueza do agronegócio: trabalho e pobreza das mulheres em territórios do agronegócio no Brasil: o caso de Cruz Alta/RS Buenos Aires: CLACSO.

Centro de Aperfeiçoamento de Pessoal de Nivel Superior. (2010). Recuperado em 05 de abril, 2016, de www.capes.gov.br.

Dias, C. M. S., \& Engers, M. E. A. (2005). Tempos e memorias de professoras alfabetizadoras. Rev. Educação, 3(57), 505-523.

Fernandes, B. M. (s/a). Os campos da pesquisa em educação do campo: espaço e 
território como categorias essenciais. Recuperado em 05 de junho, 2016 de http://portal.mec.gov.br/secad/arquivos/pdf leducacaodocampo/artigo_bernardo.pdf

Freire, P. (1987). Pedagogia do Oprimido. Rio de Janeiro, RJ: Paz e Terra.

Freitas, T. V. (2007). O cenário atual da divisão sexual do trabalho. In Silveira, M. L., \& Freitas, T. V. (Orgs). Trabalho, corpo e vida das mulheres: crítica à sociedade de mercado. São Paulo: SOF.

Frigotto, G. (2014). A cientificidade do conhecimento e os processos coletivos de transformação da realidade social. In: Caldart, R. S., \& Alentejano, P. (Orgs.). MST; Universidade e Pesquisa. São Paulo: Expressão Popular.

Instituto Nacional de Estudos e Pesquisas Educacionais Anísio Teixeira - Inep. (2007). Panorama da educação no campo. Brasília.

Hypólito, Á. M. (1997). Trabalho docente, classe social e relações de gênero. (Coleção magistério: formação e trabalho pedagógico). Campinas, SP: Papirus.

Lei complementar $n^{\circ} 30$, de 10 de janeiro de $1995 . \quad$ (1995). Resolução 001/95/CEE/MT institui-se a Universidade do Estado de Mato Grosso.

Lei $n^{o}$ 5.348, de 06 de setembro de 1988. (1988) D.O. 06.09.88. Criação do Distrito de Caramujo. http://www.sadlegislacao.mt.gov.br/Aplicativos/Sad-

Legislacao. Recuperado em 26 de maio, 2016.

Maldonado, C. A. R. (1995). UNEMAT: uma universidade para o $3^{\circ}$ milênio. Cáceres: Edições Iguapé.
Martins, J. S. (2009). Fronteira - A degradação do Outro nos confins do humano. São Paulo: Contexto.

Marx, K. (2001). O capital: crítica da economia política. Rio de Janeiro: Civilização Brasileira.

Mészáros, I. (2008) A educação para além do capital. São Paulo: Boitempo.

Molina, M. C. (2014). As análises de práticas contra hegemônicas na formação de educadores: reflexões a partir do curso de Licenciatura em Educação do Campo. In Cunha, S. J. V., \& Silva, M. A. (Orgs). $O$ método dialético na pesquisa em educação. Coleção Políticas Públicas da Educação. Campinas, SP: Autores Associados/Brasília, DF: Faculdade de Educação, Universidade de Brasília, UnB.

Molina, M. C. (2015). Expansão das licenciaturas em Educação do Campo: desafios e potencialidades. Educar em Revista, 55, 145-166.

Molina, M. C., \& Freitas. H. C. A. (2011). Avanços e desafios na construção da Educação do Campo. Em Aberto, 85(24), 5-6.

Neto, A. J. M. (2011). Formação de professores para a Educação do Campo: projetos sociais em disputa. In Rocha, M. I. A., \& Martins, A. A. (Orgs.). Educação do Campo: desafios para a formação de professores. Belo Horizonte: Autêntica Editora.

Peripolli, O. J. (2009). Expansão do capitalismo na Amazônia Norte Matogrossense: a mercantilização da terra e da escola. (Tese de Doutorado). Universidade Federal do Rio Grande do Sul.

Projeto Político Curricular do Curso de Licenciatura em Pedagogia do Campo. (2013). UNEMAT, Cáceres. 
Saffioti, H. I. B. (2013). A mulher na sociedade de classes. São Paulo: Expressão Popular.

Therrien, J. (1993). A professora leiga e o saber social. In Professor leigo: institucionalizar ou erradicar? São Paulo, Cortez.

\footnotetext{
${ }^{\text {i } U m a ~ a c a d e ̂ m i c a ~ r e l a t o u ~ q u e ~ e ́ ~ v o l u n t a ́ r i a ~ n u m a ~}$ instituição de educação infantil e que há um contrato para receber $\mathrm{R} \$ 100,00$ (cem reais) por mês pago pela professora. $\mathrm{O}$ contrato, segundo a mesma, é para ter ciência de algumas regras como: não faltar; usar roupas adequadas; etc.
}

ii Bispo Emérito da Prelazia de São Felix do Araguaia.

iii Molina (2011) defende que o "Movimento da Educação do Campo" é aquele iniciado a partir da I Encontro Nacional de Educadores e Educadoras da Reforma Agrária, momento em que é iniciado um novo rumo à educação que os movimentos sociais almejavam para os povos do campo.

${ }^{\text {iv }}$ Foram ofertados cursos de magistério do MST, e posteriormente o curso de Pedagogia da Terra na Unemat, Unijuí.

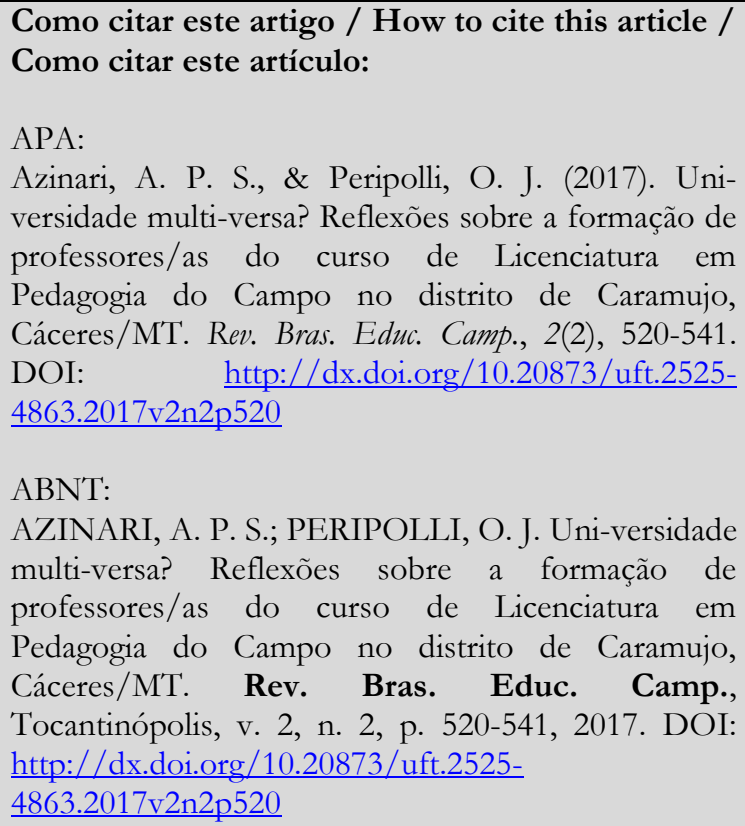
versidade multi-versa? Reflexões sobre a formação de professores/as do curso de Licenciatura em Pedagogia do Campo no distrito de Caramujo, Cáceres/MT. Rev. Bras. Educ. Camp., 2(2), 520-541. DOI: $\quad$ http://dx.doi.org/10.20873/uft.25254863.2017v2n2p520

ABNT:

AZINARI, A. P. S.; PERIPOLLI, O. J. Uni-versidade multi-versa? Reflexões sobre a formação de professores/as do curso de Licenciatura em Pedagogia do Campo no distrito de Caramujo, Cáceres/MT. Rev. Bras. Educ. Camp., Tocantinópolis, v. 2, n. 2, p. 520-541, 2017. DOI: http://dx.doi.org/10.20873/uft.2525$\underline{4863.2017 \mathrm{v} 2 \mathrm{n} 2 \mathrm{p} 520}$

\section{ORCID}

Amanda Pereira da Silva Azinari

iD http://orcid.org/0000-0001-9345-0219

Odimar João Peripolli

(iD) http://orcid.org/0000-0002-0596-6213

Recebido em: 02/04/2017

Aprovado em: 21/05/2017

Publicado em: 31/07/ 2017 